\title{
Data mining tools in identifying the components of the microstructure of compacted graphite iron based on the content of alloying elements
}

\author{
Dorota Wilk-Kolodziejczyk ${ }^{1} \cdot$ Krzysztof Regulski $^{1}$ - Grzegorz Gumienny ${ }^{3} \cdot$ Barbara Kacprzyk $^{3}$. \\ Stanislawa Kluska-Nawarecka ${ }^{2} \cdot$ Krzysztof Jaskowiec $^{2}$
}

Received: 23 August 2017 / Accepted: 20 November 2017 / Published online: 7 December 2017

(C) The Author(s) 2017. This article is an open access publication

\begin{abstract}
The application of data mining techniques in the design of modern foundry materials allows achieving higher product quality indicators. Designing of a new product always requires thorough knowledge of the effect of alloying elements on the microstructure and hence also on the properties of the examined material. The conducted experimental studies allow for a qualitative assessment of the indicated relationships, but it is the use of intelligent computational techniques that enables building an approximation model of the microstructure and, owing to this, make predictions with high precision. The developed model of prediction supports the technology-related decisions as early as at the stage of casting design and is considered the first step in selecting the type of material used.
\end{abstract}

Keywords Compacted graphite iron · Data mining $\cdot$ Support vector machine $\cdot$ Decision trees $\cdot$ Artificial neural networks

\section{Introduction}

Materials Engineering is the field of science characterized by an interdisciplinary nature. It uses the knowledge of basic sciences (physics, chemistry, biology) to improve engineering materials. Many modern solutions and designs can be created only with the use of new materials. Owing to the development of materials engineering, we now have materials that allow for the construction of machines working under most extreme conditions. The functional

Dorota Wilk-Kolodziejczyk

dwilk@agh.edu.pl

Krzysztof Regulski

regulski@agh.edu.pl

Grzegorz Gumienny

grzegorz.gumienny@p.lodz.pl

Stanislawa Kluska-Nawarecka

stanislawa.kluska@iod.krakow.pl

Krzysztof Jaskowiec

krzysztof.jaskowiec@iod.krakow.pl

1 AGH University of Science and Technology, Krakow, Poland

2 Foundry Research Institute, Krakow, Zakopiańska 73, Poland

3 Lodz University of Technology, Lodz, Poland properties of the objects and devices that are currently in use depend on the properties of materials from which they have been made, while the properties of materials depend on the structure which is formed in the manufacturing process.

With models predicting the microstructure, it becomes possible to improve and automate the process of designing new materials with desired properties. It is essential to define the rules, laws, and relationships existing in the specified area, and then the data mining tools can support the experimental research process. Alloying additives forming part of the material composition influence shaping of the compacted graphite iron structure. However, the relationships are not of a linear nature and, as will be shown later, the traditional methods of regression do not work.

Where statistical tools fail to do their work, models developed in the field of artificial intelligence can prove to be applicable. Very popular in recent years, data mining techniques [1,2] and machine learning [3] are based on similar principles. To create models and carry out their calibration (training), historical empirical data is used. Based on this data, models are constructed and their task is to capture the data that occur in the relationships between various variables [4-6]. These relationships are used to create prediction models (where the dependent variable is of a quantitative type) or classification models (where the dependent variable is discrete or categorical). The common 
goal of these methods is to provide the possibility of determining the unknown value of the dependent variable based on the values taken by the explanatory variables [7]. In the case under discussion, it is the determination of the content of phase constituents in the microstructure, based on the percent values of the chemical composition and wall thickness. There are very few publications on the influence of alloying elements on the microstructure and properties of compacted graphite iron [8] and [9].

Compacted graphite iron (CGI) occupies a special place as the casting material. This is due to a specific form of graphite and large contact surface with the matrix. The result is the tendency of this cast iron to direct ferritization and a complex of the most interesting properties. Compared to gray iron, CGI has higher mechanical properties and improved ductility. The microstructure of the matrix is less sensitive to the thickness of the casting wall. Compared to ductile iron, the cast iron with compacted graphite has a lower coefficient of thermal expansion, higher thermal conductivity, greater resistance to dynamic changes in temperature, higher vibration damping capacity, and better castability. All these advantages predestine this material for a variety of applications. The first utilitarian use of this cast iron covered brake discs for high-speed railway stock. Currently, this material is mainly used for the construction of blocks of internal combustion engines, exhaust manifolds, and the like cast automotive parts. The interesting complex of properties obtained in this type of cast iron is the object of intensive research and numerous publications [10-17]. By changing the chemical composition, it becomes possible to modify in a wide range the cast iron microstructure, and consequently its properties. There is a fairly large group of publications describing the possibility of obtaining ausferrite in the cast iron with compacted or vermicular graphite and obtain AVI (Vermicular Austempered Iron) or CAVI (Carbidic Vermicular Austempered Iron) [18-21]. Ausferrite is a mixture of bainitic ferrite and austenite supersaturated with carbon. The amount of retained austenite in ADI can be up to $40 \%$. It is a desirable component of the microstructure, undergoing under the effect of stress a twinning-induced martensitic transformation with the resulting strengthening. To produce ausferrite, the casting has to be subjected to a heat treatment, which consists in isothermal quenching and holding within the temperature range of austenite $\rightarrow$ bainite transformation. There is also an alternative method of obtaining ausferrite involving a modification of the cast iron chemical composition, using for this purpose molybdenum, copper or nickel added in appropriate proportions.

The use of models of artificial intelligence in microstructure prediction is the subject relatively popular. There are various embodiments of the neural networks to approximate the cement structure [22] and [23], and well-known is also

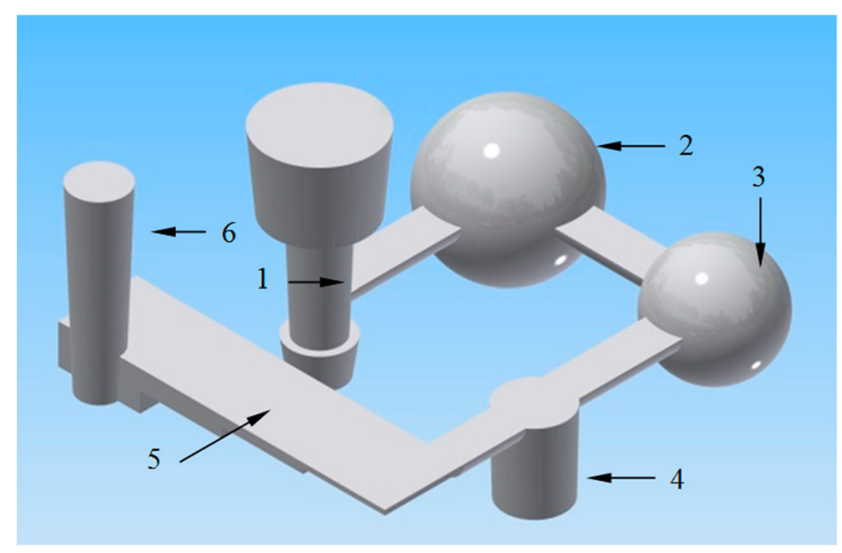

Fig. 1 Schematic layout of mold components for the vermicularizing treatment of cast iron by Inmold process; 1-downgate, 2-reaction chamber, 3 - mixing chamber, 4 - control chamber, 5-pilot casting, 6-overflow

the use of support vector machine (SVM) in classification of the structure of aluminum alloys (AA3002) [24] or zinc alloys (Zircaloy-2) [25]. Quite widespread is the use of cellular automata in the simulation of microstructure evolution [26] and [27].

\section{Research methodology}

The test metal was melted in an electric induction medium frequency furnace with crucible of $30 \mathrm{~kg}$ capacity. The vermicularizing treatment was made by Inmold process. The charge for the furnace consisted of special-purpose pig iron with sulfur concentration of $0.01 \%$; the charge also contained FeSi75 ferrosilicon, FeMn75 ferromanganese and technically pure $\mathrm{Mo}, \mathrm{Cu}, \mathrm{Ni}$ and $\mathrm{Cr}$. The cast iron at a temperature of about $1480^{\circ} \mathrm{C}$ was poured to a sand mold shown in Fig. 1.

The gating system incorporates the spherically shaped reaction chamber (2) with $\phi 85 \mathrm{~mm}$ diameter. In this chamber, the Lamet 5504 magnesium master alloy made by Elkem Norway is placed. The composition of the master alloy is shown in Table 1. Behind the reaction chamber, there is the mixing chamber (3), ensuring a very thorough dissolution of the master alloy, and control chamber (4) where the cast iron cooling and solidification process is recorded. The test casting (5) has a stepped configuration

Table 1 The chemical composition of master alloy

Chemical composition, wt $\%$

\begin{tabular}{llllll}
\hline $\mathrm{Si}$ & $\mathrm{Mg}$ & $\mathrm{Ca}$ & $\mathrm{La}$ & $\mathrm{Al}$ & $\mathrm{Fe}$ \\
\hline $44-48$ & $5-6$ & $0.4-0.6$ & $0.25-0.40$ & $0.8-1.2$ & rest \\
\hline
\end{tabular}


Table 2 The chemical composition of CGI tested

\begin{tabular}{lll}
\hline \multirow{4}{*}{ Chemical } & $\mathrm{Cr}$ & $0-2.81$ \\
& $\mathrm{Ni}$ & $0-21.04$ \\
Composition & $\mathrm{Cu}$ & $0-3.80$ \\
& $\mathrm{Mo}$ & $0-2.44$ \\
$\%$ & $\mathrm{Mg}$ & $0.015-0.023$ \\
& $\mathrm{Mn}$ & $0.03-1.31$ \\
& $\mathrm{Si}$ & $2.28-2.71$ \\
& $\mathrm{C}$ & $2.91-3.82$ \\
\hline
\end{tabular}

with the wall thickness of $3,6,12$ and $24 \mathrm{~mm}$. The range of the chemical composition of the tested cast iron is shown in Table 2. In the literature, the chamber is most often rectangular. However, in the paper [28], the effect of the shape of the reaction chamber on the graphite shape in the cast iron obtained by Inmold technology was investigated. The chambers have rectangular, cylindrical, and spherical shape. It was shown that the highest graphite coefficient was in cast iron obtained in the mould where the reaction chamber was spherical.

The wide range of the chemical composition used in the tests enabled obtaining the microstructure of a ferriticpearlitic, pearlitic, austenitic, martensitic, and ausferritic type. Samples for metallographic examinations were cut out from the central part of the stepped casting. Metallographic examinations were carried out at a magnification of 500x under an Eclipse MA200 Nikon optical microscope. The surface content of carbides was examined using an NISElements BR image analyzer. Hardness of the cast iron was measured with an HPO-2400 durometer under the following conditions: ball diameter $\phi=2.5 \mathrm{~mm}$, load $\mathrm{F}=1840 \mathrm{~N}$.

\section{Data analysis}

There are many dependent variables in the studied problem (the individual components of the matrix) and one (wall thickness) or more (chemical composition) explanatory variables. It is a system very difficult for analysis by the methods of regression, which allow using only one dependent variable.

\subsection{Regression and MARSplines}

Studies of the relationships between variables were performed using Pearson's linear correlation coefficient. Correlations for the wall thickness were too weak to make building of regression models possible, and therefore it was necessary to introduce data on the chemical composition to the model developed (Tables 3 and 4).

The correlation coefficients seem promising and by selecting the strongest correlations, respective scatter plots can be made (Fig. 2).

In each of the cases described, the relationships are well visible, but configurations of individual points indicate a strongly non-linear character of these relationships.

A MARSplines model (spline regression) based on all the variables was developed.

Multivariate Adaptive Regression Splines (MARSplines), being a generalized form of regression model, aim to create a model for the prediction of dependent variable based on the volatility of explanatory variables [29-33]. For the analysis of MARSplines, it is not necessary to have a priori knowledge about the form of the relationship between variables. The relationship is determined from the data using basis functions. MARSplines is a multiple linear regression composed of segments. The boundaries of segments are determined from the data and define areas subject to individual linear equations [34] and [35].

Using MARSplines, very poor results of the fit were achieved. The only variable that has been defined as statistically significant was the Mo content. The only notable model was the model for pearlite with $42 \%$ fit and for ausferrite with $90 \%$ fit $\left(R^{2}=0.9\right)$.

Let us now examine the model for ausferrite.

$$
\text { ausferrite }=84,28-60,2 * \max (0 ; 1,4-M o)
$$

Analyzing the scatter plot, it is clear that this fit is false as a result of the selection of cases. If the model was built on the basis of samples containing molybdenum (removing the cases in which the content of Mo=0), the chart would be as shown in Fig. 3.

The fit is in this case unsatisfactory. By examining the data set, one can specify the cases for individual factors (explanatory variables), in which the content is different

Table 3 A map of correlations

\begin{tabular}{lllllll}
\hline & Ferrite & Pearlite & Carbides & Martensite & Ausferrite & Austenite \\
\hline $\mathrm{Mn}$ & 0.25 & 0.38 & -0.02 & 0.075 & -0.46 & 0.07 \\
$\mathrm{Cr}$ & -0.16 & 0.28 & 0.74 & -0.11 & -0.28 & -0.10 \\
$\mathrm{Cu}$ & -0.26 & -0.06 & -0.14 & -0.19 & 0.36 & -0.18 \\
$\mathrm{Ni}$ & -0.17 & -0.36 & -0.24 & 0.40 & -0.26 & 0.93 \\
$\mathrm{Mo}$ & -0.36 & -0.63 & -0.07 & -0.25 & 0.915 & -0.24 \\
Thickness & 0.20 & -0.03 & -0.22 & 0.01 & 0.02 & -0.01 \\
\hline
\end{tabular}


Table 4 A map of correlations

\begin{tabular}{lllllll}
\hline & Ferrite & Pearlite & Carbides & Martensite & Ausferrite & Austenite \\
\hline $\begin{array}{l}\text { Mean } \\
\text { (observed) }\end{array}$ & 8.21 & 34.57 & 8.09 & 7.19 & 35.27 & 6.59 \\
$\begin{array}{l}\text { Standard } \\
\text { deviation } \\
\text { (observed) }\end{array}$ & 14.47 & 35.57 & 13.42 & 23.35 & 43.93 & 22.76 \\
$\begin{array}{l}\text { Mean } \\
\text { (predicted) }\end{array}$ & 8.21 & 34.57 & 8.09 & 7.19 & 35.27 & 6.59 \\
$\begin{array}{l}\text { Standard } \\
\text { deviation } \\
\text { (predicted) }\end{array}$ & 5.55 & 23.41 & 1.34 & 6.00 & 41.68 & 5.61 \\
$\begin{array}{l}\text { Coefficient of } \\
\text { determination }\end{array}$ & 0.15 & 0.43 & 0.01 & 0.07 & 0.90 & \\
$R^{2}$ & & & & & \\
\hline
\end{tabular}
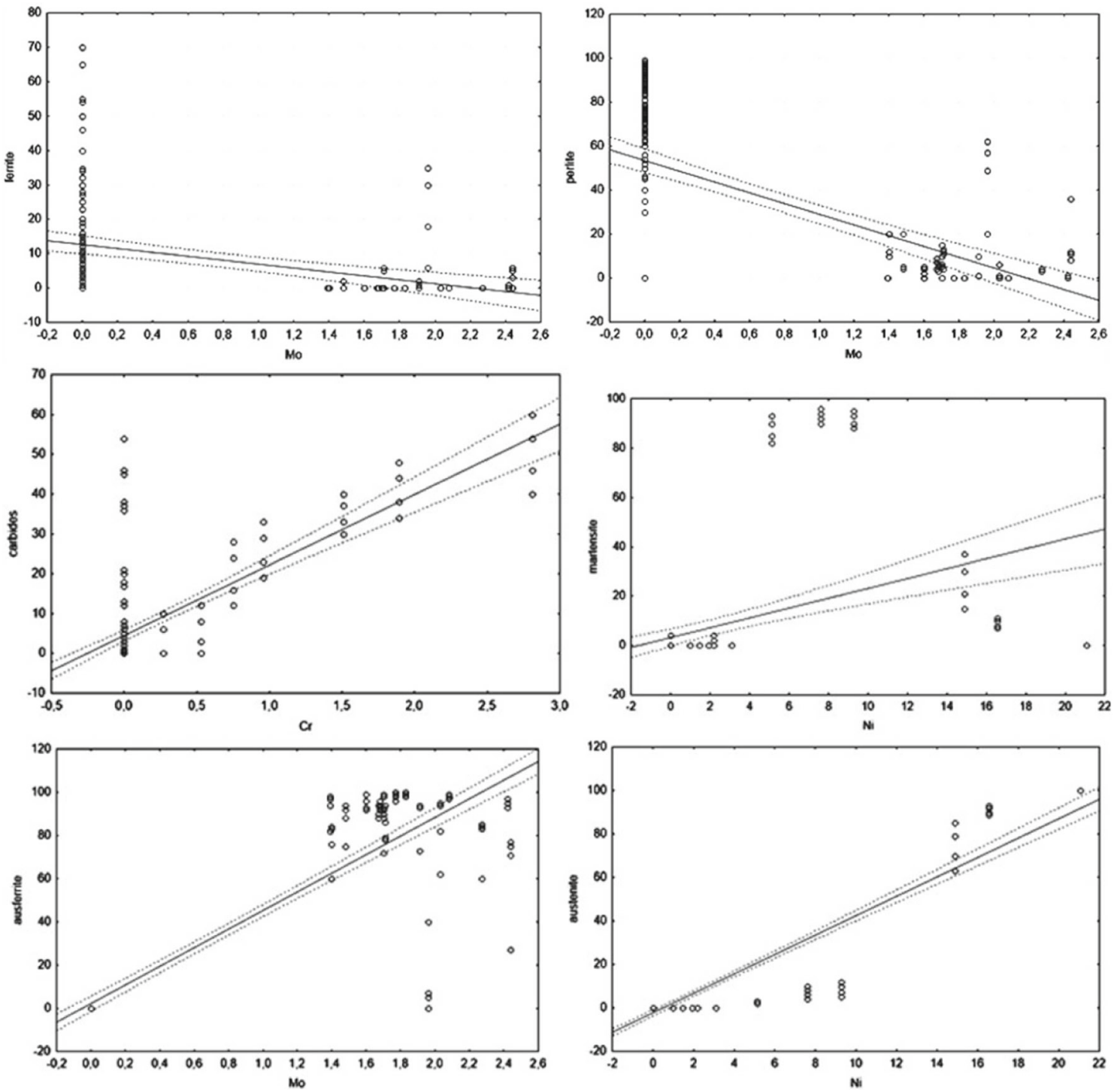

Fig. 2 Scatter plots for Mo: ferrite; Mo: pearlite; $\mathrm{Cr}$ —carbides; $\mathrm{Ni}$-martensite; $\mathrm{Mo}$-ausferrite; Ni—austenite 


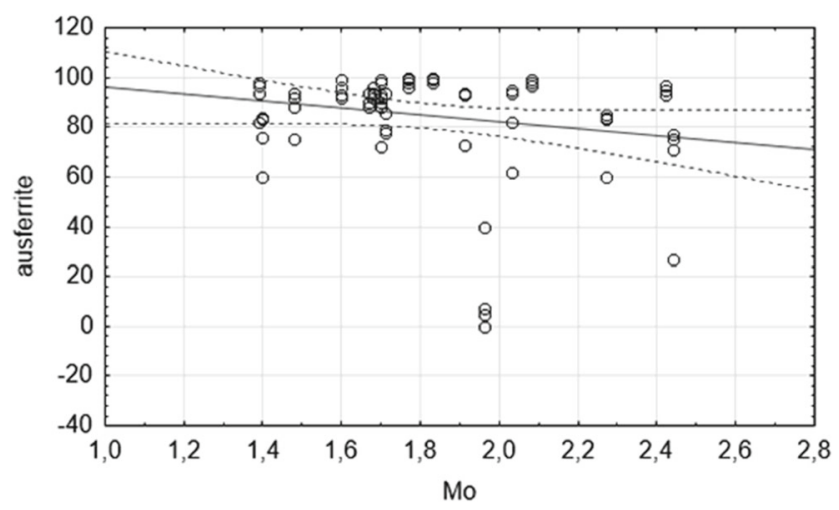

Fig. 3 A molybdenum : ausferrite scatter plot for cases containing molybdenum

from zero. Analyzing in this way the influence of individual alloying elements on the components of microstructure (Fig. 4), the following conclusions are drawn:

- Cr: an increase in its content favors the formation of carbides,
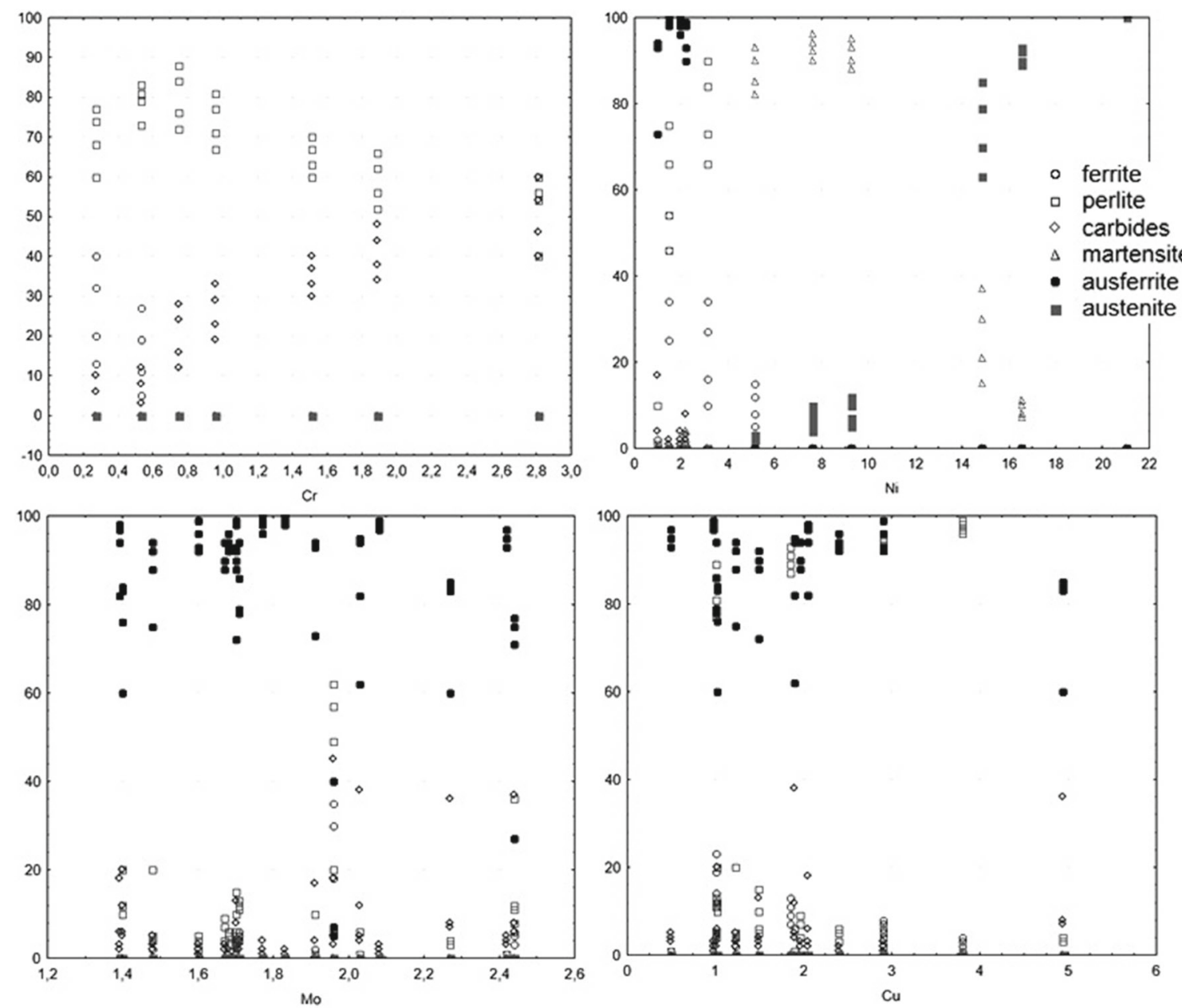

- Ni: present in small concentrations it supports the formation of ferrite and pearlite, whereas in the range of 5-9\% it promotes the formation of martensite; in higher concentrations it behaves as an austenite-forming element,

- Mo: it allows for the formation of ausferrite.

- $\mathrm{Cu}$ : it is the strongest pearlite-forming additive.

The quality of predictive models can be assessed in each case by the coefficient of determination $R^{2}$. It determines the extent to which the model is fit to the empirical data, that is, the degree to which it is capable of explaining the variability of the dependent variable.

\subsection{Artificial neural networks}

Artificial neural networks are mathematical structures consisting of layers of neurons that are simple calculation tools based on the function of activation and weights for multiplication of the input signals. The principle of operation of neural networks is based on processing a set of input signals independently by each neuron in each layer, where the decisive influence on the output signal have the weights on

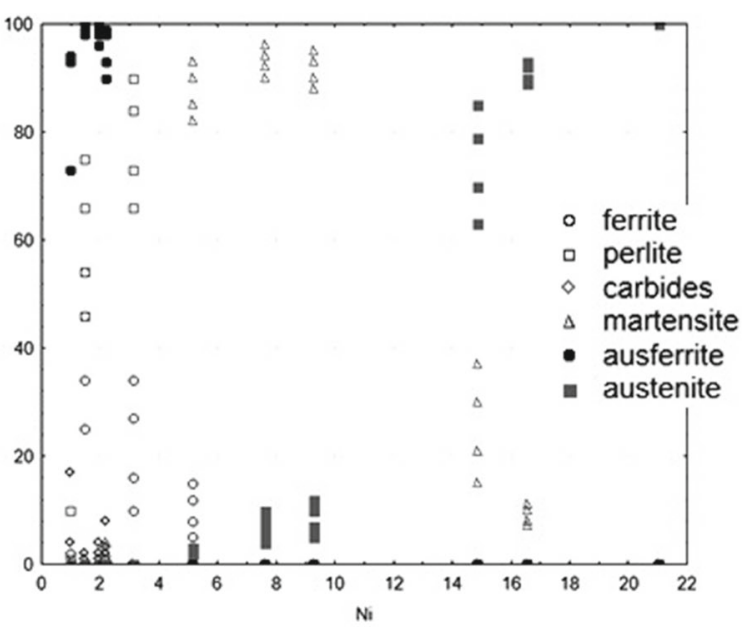

Fig. 4 The effect of various alloying elements on microstructure 
Table 5 The results yielded by artificial neural networks

\begin{tabular}{|c|c|c|c|}
\hline $\begin{array}{l}\text { Error } \\
\text { (validation) }\end{array}$ & 179.2556 & & \\
\hline $\begin{array}{l}\text { Error } \\
\text { (testing) }\end{array}$ & 57.22190 & & \\
\hline $\begin{array}{l}\text { Error } \\
\text { (training) }\end{array}$ & 217.0059 & & \\
\hline $\begin{array}{l}\text { Quality } \\
\text { (validation) }\end{array}$ & 0.907 & $\begin{array}{l}\text { Activation } \\
\text { (output) }\end{array}$ & Logistic \\
\hline $\begin{array}{l}\text { Quality } \\
\text { (testing) }\end{array}$ & 0.989 & $\begin{array}{l}\text { Activation } \\
\text { (hidden) }\end{array}$ & Tanh \\
\hline $\begin{array}{l}\text { Quality } \\
\text { (training) }\end{array}$ & 0.974 & $\begin{array}{l}\text { Error } \\
\text { function }\end{array}$ & SOS \\
\hline $\begin{array}{l}\text { Network } \\
\text { name }\end{array}$ & MLP 6-11-6 & $\begin{array}{l}\text { Learning } \\
\text { algorithm }\end{array}$ & BFGS 146 \\
\hline
\end{tabular}

the inputs to each neuron. Neurons are connected together in series between the layers. Literature on artificial neural networks is very extensive, as this is the tool known and applied for many years in the data analysis. It is enough to give a few examples of the application of neural networks in metals engineering [36-40]. The essence of the training of neural network is based on the modification of weights at the inputs to the neurons. The modification is performed with the learning algorithms based on optimization of the root mean square error at the output from the network with respect to the experimental observations. The modification of weights is done iteratively, and the training iterations are called epochs. There is a risk of overtraining the network; this happens when the model becomes too fit to empirical data and loses its ability to make generalizations in cases which have not been reflected in the training data set.

The described analysis uses the model of artificial neural network which has yielded very satisfactory results (Table 5).

Let us keep in mind that, in fact, neural networks do not provide the possibility of developing a model with more than one output variable. The technique of the network training used here is applied in sequence to several models, where each of these models has a different output variable, and then the same network architectures and weights of neurons are tested for different output variables. In the case under discussion, the fits for each component are presented in Table 6.

For analysis, the MLP 6-11-6 network has been chosen. The notation defines the network architecture: 6 input neurons (one signal for each variable); 11 neurons in the hidden layer and 6 neurons at the output specifying the content of individual phase constituents. As a function of activation, the network of a given architecture uses hyperbolic tangent function in the hidden layer and logistic function in the output layer. As a method for the error calculation, the sum of squares is used, and as a training algorithm-an optimization method based on the Broyden-Fletcher-GoldfarbShanno (BFGS) algorithm. Thus, designed network reflects the input data with the correlation of from 0.87 for ausferrite to 0.99 for austenite and martensite, resulting for some constituents in $R^{2}=0.99$, which is a nearly perfect result.

Table 6 ANN fit for individual components

\begin{tabular}{|c|c|c|c|c|c|c|}
\hline & Austenite & Ausferrite & Martensite & Carbides & Pearlite & Ferrite \\
\hline $\begin{array}{l}\text { Mean of squared } \\
\text { residuals }\end{array}$ & 1 & 376.04 & 0.5 & 8 & 23.48 & 25.27 \\
\hline Mean absolute & & & & & & \\
\hline error & 0 & 7.22 & 0.3 & 2 & 3.08 & 1.91 \\
\hline $\begin{array}{l}\text { Relative mean } \\
\text { square error }\end{array}$ & 169362563 & 0.63 & 618320.8 & 92073395 & 1919011021.96 & 530368731299.93 \\
\hline $\begin{array}{l}\text { Relative mean } \\
\text { deviation }\end{array}$ & 1209 & 0.66 & 72.2 & 1241 & 6513.89 & 115775.56 \\
\hline $\begin{array}{l}\text { Correlation } \\
\text { coefficient }\end{array}$ & 0.99 & 0.93 & 0.99 & 0.99 & 0.99 & 0.95 \\
\hline $\begin{array}{l}\text { Coefficient of } \\
\text { determination } R^{2}\end{array}$ & 0.99 & 0.87 & 0.99 & 0.96 & 0.98 & 0.90 \\
\hline
\end{tabular}

Italicized entries are the most important indicators 
The network prediction charts are show in Fig. 5.

A typical feature of this model is that its worst prediction is for ausferrite. Obviously, the network trained on the basis of all constituents is unable to correctly predict the content of ausferrite. Presumably, the relationships valid for this particular constituent are different than for other constituents.

\subsection{Support vector machine (SVM)}

In non-linear models, the methods of regression become less accurate. An alternative to artificial neural networks is the method of Support Vector Machine (SVM), very fashionable in recent years. This is a binary classifier defining from the training data the widest possible boundary between classes. In the applied strategy of cascade classifiers, this tool is also suitable for solving the problems where the dependent variable can take multiple classes of values. In the case of continuous dependent variable, the algorithm uses discretization for a fixed number of intervals. A solution to the problem of non-linearity is kernel trick mapping of training vectors to an area of larger dimension, where one can expect them to have linear separability. The calculations are carried out using kernel functions [41] and [42]. SVM allows building models for a single dependent variable. Hence, the necessity of approximation using six different models built on the same predictors. The models and the quality of predictions are summarized in Table 7 and visualized in respective graphs (Fig. 6).
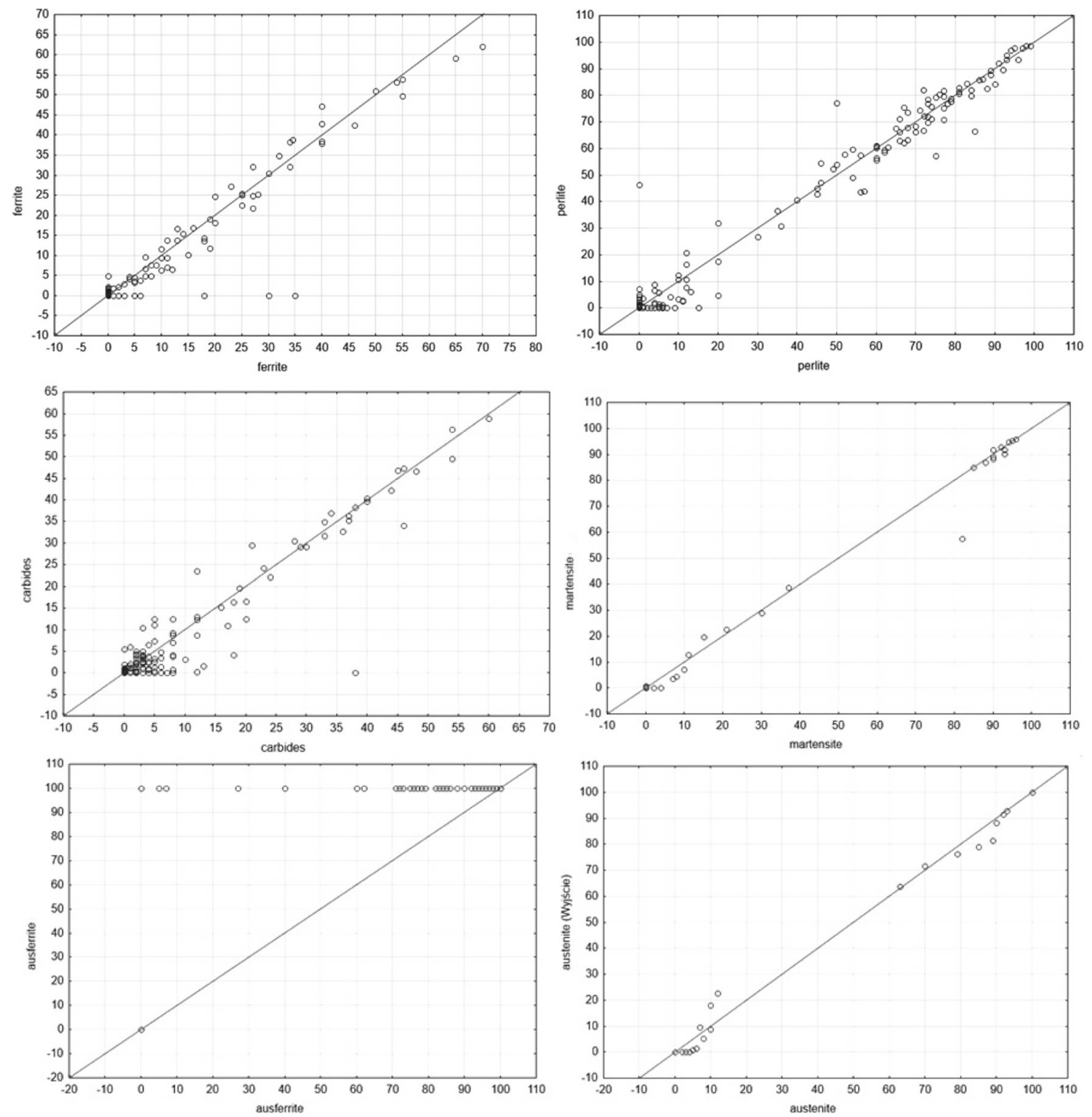

Fig. 5 Predicting the input variables for MLP 6-11-6 network 
Table 7 The SVM models for individual components

\begin{tabular}{|c|c|c|c|c|c|c|}
\hline Model specification & Ferrite & Pearlite & Carbides & Martensite & Ausferrite & Austenite \\
\hline Number of predictors & 6 & 6 & 6 & 6 & 6 & 6 \\
\hline SVM type & $\begin{array}{l}\text { Regresion of } \\
\text { type } 1\end{array}$ & $\begin{array}{l}\text { Regresion of } \\
\text { type } 1\end{array}$ & $\begin{array}{l}\text { Regresion of } \\
\text { type } 1\end{array}$ & $\begin{array}{l}\text { Regresion of } \\
\text { type } 1\end{array}$ & $\begin{array}{l}\text { Regresion of } \\
\text { type } 1\end{array}$ & $\begin{array}{l}\text { Regresion of } \\
\text { type } 1\end{array}$ \\
\hline Kernel type & $\mathrm{RBF}$ & $\mathrm{RBF}$ & $\mathrm{RBF}$ & $\mathrm{RBF}$ & $\mathrm{RBF}$ & $\mathrm{RBF}$ \\
\hline WN number & $\begin{array}{l}56 \\
(41 \text { related })\end{array}$ & $\begin{array}{l}72 \\
(60 \text { related })\end{array}$ & $\begin{array}{l}45 \\
(28 \text { related })\end{array}$ & $\begin{array}{l}34 \\
(24 \text { related) }\end{array}$ & $\begin{array}{l}50 \\
\text { (31 related) }\end{array}$ & $\begin{array}{l}33 \\
(19 \text { related })\end{array}$ \\
\hline Observed mean & 7.56 & 32.88 & 8.00 & 2.93 & 37.74 & 10.67 \\
\hline Predicted mean & 5.82 & 31.27 & 6.00 & 3.09 & 43.22 & 8.19 \\
\hline $\begin{array}{l}\text { Observed standard } \\
\text { deviation }\end{array}$ & 13.98 & 37.10 & 13.37 & 12.99 & 45.19 & 29.70 \\
\hline $\begin{array}{l}\text { Predicted standard } \\
\text { deviation }\end{array}$ & 9.40 & 35.48 & 10.78 & 7.32 & 44.79 & 25.19 \\
\hline $\begin{array}{l}\text { Root mean square } \\
\text { error }\end{array}$ & 65.86 & 189.29 & 74.98 & 135.84 & 421.25 & 63.20 \\
\hline Mean of the error & 1.74 & 1.62 & 2.00 & -0.16 & -5.48 & 2.48 \\
\hline $\begin{array}{l}\text { Standard deviation } \\
\text { of the error }\end{array}$ & 8.02 & 13.82 & 8.52 & 11.79 & 20.01 & 7.64 \\
\hline Mean absolute error & 4.72 & 8.49 & 4.42 & 5.02 & 10.05 & 4.64 \\
\hline $\begin{array}{l}\text { Ratio of standard } \\
\text { deviations }\end{array}$ & 0.57 & 0.37 & 0.64 & 0.91 & 0.44 & 0.26 \\
\hline Correlation & 0.84 & 0.93 & 0.77 & 0.44 & 0.90 & 0.97 \\
\hline $\begin{array}{l}\text { Coefficient of } \\
\text { determination } R^{2}\end{array}$ & 0.70 & 0.86 & 0.59 & 0.19 & 0.81 & 0.95 \\
\hline
\end{tabular}

Italicized entries are the most important indicators

In the majority of cases, SVM gives the fit worse than neural networks. Based on the scatter plot (fit), it can be noted, however, that in the case of ausferrite, training of the model is much more efficient, despite the worse coefficient of determination $R^{2}$.

Despite the relatively accurate results, both ANN and SVM methods have one common drawback. As a model, they actually represent a black box. Their character is difficult to interpret for a man, so their use is limited to the implementation of computer tools, and the only knowledge that can be drawn is in the form of numerical results [43]. The situation is quite different in the case of decision trees (Table 8).

\subsection{CART trees}

CART Trees (Classification And Regression Trees) belong to a group of algorithms of the induction of decision trees. Decision trees are a form of knowledge representation relatively easy to interpret both at the stage of knowledge acquisition (data mining) and also in the phase of its use in the decision-making process. The algorithm has already been repeatedly described in the literature [44-46]. The tree induction algorithm is iteratively dividing the training data set into partitions, and the division goes on until all the partitions become uniform, which can be determined from the least squared deviation in the case of regression trees and the cost of resubstitution. During the construction of regression trees, the low value of the resubstitution cost is provided by the dependent variable whose value is close to or equal to the average in a given leaf. The best division of the node is the one in which there is the largest decline in the cost of resubstitution. CART tree is a graphical representation of the rules, where each node represents a test on the internal variables, each arc represents a single result of a test, each leaf represents a single class of values. Here, it should be added that in a properly built model, to one dedicated node are always assigned higher values, and to the second node, the values lower than the values in the parent node. The division is based on the variance or standard deviation. The node becomes most homogeneous in the situation when all the cases contained therein are equal to the average. In a manner similar to the classification trees, the division of the tree begins with the whole set of observations and theoretically ends when every case is assigned to a separate leaf. Generally speaking, the cost of resubstitution decreases with the increasing number of end nodes in the model. 

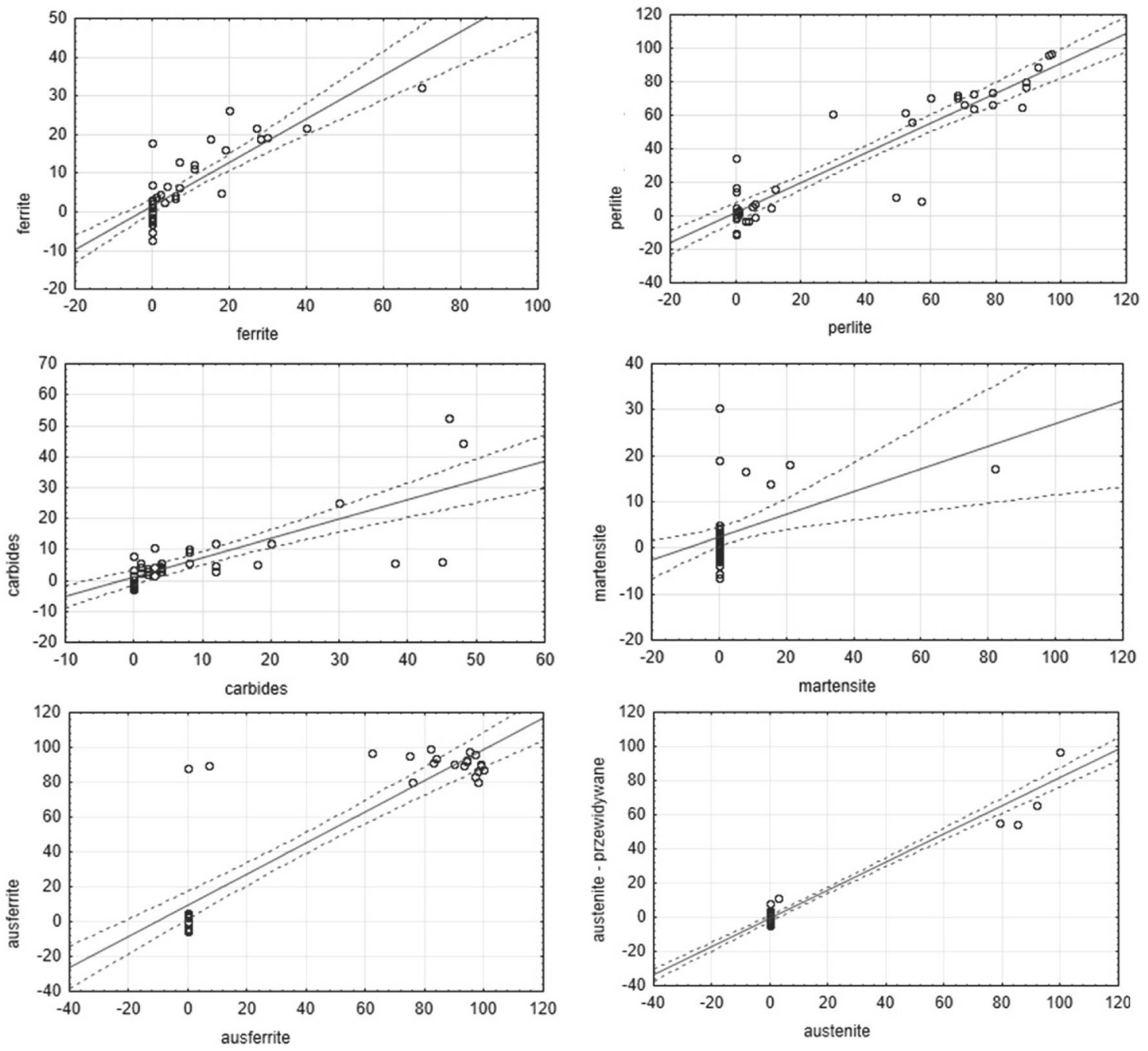

Fig. 6 Predicting the input variables for SVM models

Regression trees are usually chosen as a method of prediction taking into consideration the advantages offered by these models, which include: (1) no need to verify the assumptions concerning the form of relationship or the normality of the distribution of variables; (2) no need for recoding and standar- dization of input variables; (3) high utility of models as tools for the formalization of knowledge-easy interpretation.

Like in previous models, also in the CART trees, each dependent variable must be treated separately, and therefore, six independent trees are to be built for the same predictors.

Table 8 CART fit for individual components

\begin{tabular}{|c|c|c|c|c|c|c|}
\hline & Austenite & Ausferrite & Martensite & Carbides & Pearlite & Ferrite \\
\hline Mean of squared residuals & 14.24 & 195.91 & 15.25 & 82.76 & 126.39 & 74.72 \\
\hline Mean absolute error & 1.21 & 3.99 & 1.30 & 5.89 & 6.98 & 5.32 \\
\hline Relative mean square error & 47.59 & 0.03 & 0.00 & 2.41 & 1.35 & 7.55 \\
\hline Relative mean deviation & 2.05 & 0.05 & 0.00 & 1.04 & 0.31 & 0.88 \\
\hline Correlation coefficient & 0.99 & 0.91 & 0.99 & 0.80 & 0.95 & 0.84 \\
\hline Coefficient of determination $R^{2}$ & 0.98 & 0.83 & 0.98 & 0.64 & 0.90 & 0.71 \\
\hline
\end{tabular}

Italicized entries are the most important indicators 
Fig. 7 The validity of factors predicted by CART for individual components
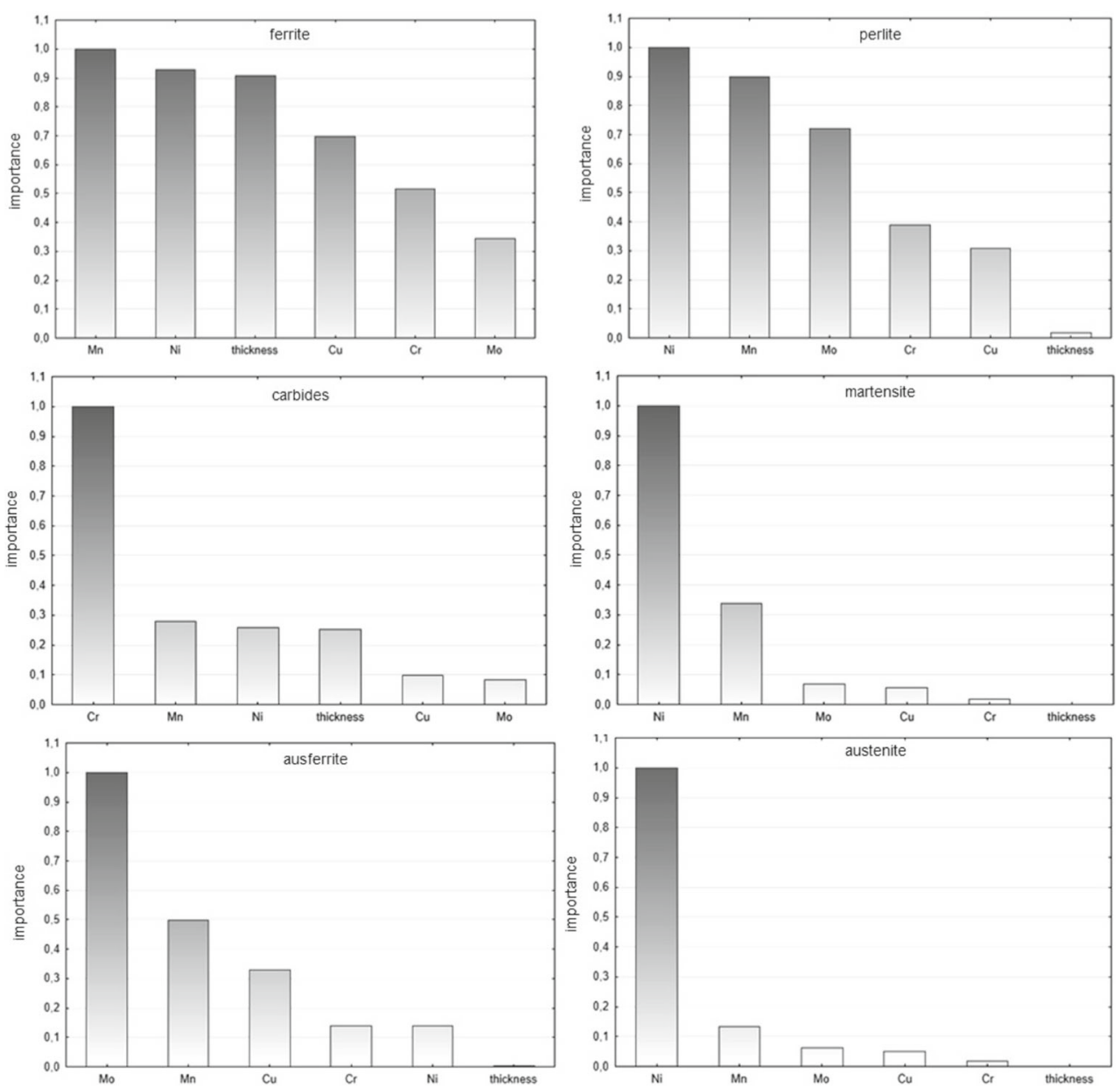

CART model is the best to predict austenite and martensite and the worst to predict carbides and ferrite.

CART models do not show a better fit than the models presented previously, but they have one important advantagethey allow the user to read complicated relationships between numerous predictors. They also allow keeping track of the importance of individual factors. For example-examining the impact of casting wall thickness, the following relationships can be observed for different microstructural constituents:

- ferrite: higher content is recommended for heavywalled castings;
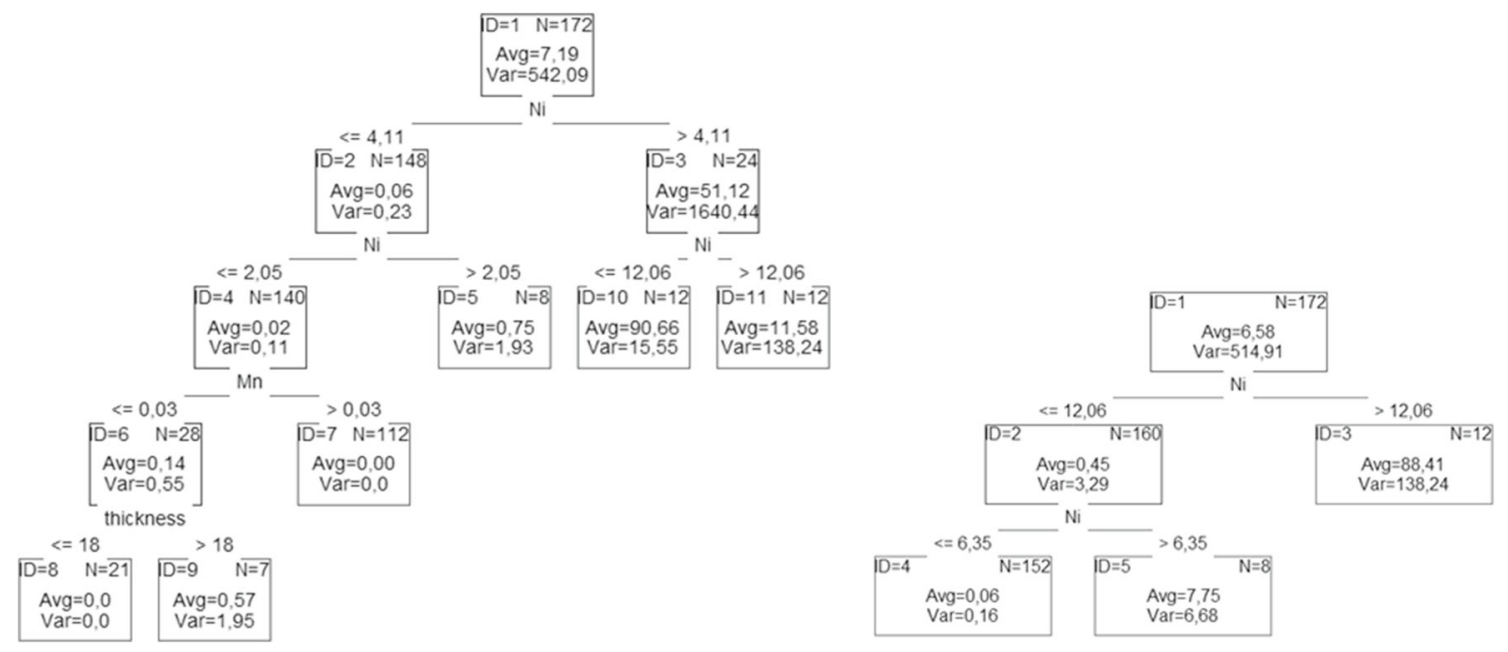

Fig. 8 CART tree obtained for: a martensite $R^{2}=0.98, \mathbf{b}$ austenite $R^{2}=0.98$ 
- pearlite: wall thickness is of no concern;

- carbides: heavy sections in castings with a low content of $\mathrm{Cr}$ reduce the content of carbides;

- martensite: in castings with a low content of $\mathrm{Ni}$ and $\mathrm{Mn}$, the wall thickness above $12 \mathrm{~mm}$ supports the presence of martensite;

- ausferrite: thickness has no effect on the content of ausferrite (only Mo);

- austenite: thickness has no effect on the content of austenite (only Ni).

Similarly, we can study the influence of alloying elements in mutual interactions-option in other models not available. Each of the trees will independently evaluate the validity of the predictors; a comparison of the validity is shown in Fig. 7.

The best models of trees for the martensite and austenite are illustrated by the diagrams in Fig. 8. In both cases, the coefficient of determination is $R^{2}=0.98$, which is the result slightly inferior to ANN, but superior to SVM.

Decision trees as a graphical representation of the rules can be saved in a text form. Rules allowing for prediction of the content of each phase constituent together form a knowledge base that allows for the identification of AVI microstructural constituents based on the cast iron chemical composition. Applying trees or rules, user can predict the

Table 9 CART fit for individual components

\begin{tabular}{lll}
\hline & Model & $\begin{array}{l}\text { Coefficient of } \\
\text { determination } R^{2}\end{array}$ \\
\hline \multirow{4}{*}{ Austenite } & ANN & 0.99 \\
& SVM & 0.95 \\
Ausferrite & CART & 0.98 \\
& ANN & 0.87 \\
Martensite & SVM & 0.81 \\
Carbides & CART & 0.83 \\
& ANN & 0.99 \\
Pearlite & SVM & 0.19 \\
& CART & 0.98 \\
Ferrite & ANN & 0.96 \\
& SVM & 0.59 \\
& CART & 0.64 \\
& ANN & 0.98 \\
& SVM & 0.86 \\
& CART & 0.90 \\
& ANN & 0.90 \\
& SVM & 0.70 \\
CART & 0.71 \\
\hline
\end{tabular}

microstructure, even without the use of other computer tools. A sample rule derived from the tree for the martensite will have the following form (Fig. 8, left branch):

$$
\begin{aligned}
& \text { if }(N i \leq 2.05) \\
& \text { and }(M n \leq 0.03) \\
& \text { and }(\text { thickness } \leq 18) \\
& \text { then }(\text { martensite; } A V G=0.0 ; V A R=0.0) \\
& \text { if }(N i \leq 2.05) \\
& \text { and }(M n \leq 0.03) \\
& \text { and }(\text { thickness }>18) \\
& \text { then }(\text { martensite; } A V G=0.57 ; V A R=1.95)
\end{aligned}
$$

\section{Conclusions}

For data derived from the studies of AVI iron, devoted mainly to the effect of alloying elements and casting wall thickness on the matrix components (microstructure), the following models were used:

- linear regression models,

- segmental regression models with MARSplines algorithm,

- models of artificial neural networks,

- models based on the method of support vector machine (SVM),

- models using classification and regression trees(CART).

The best results in the approximation, the user can obtain working on the hybrid models, where the best model is selected for individual components. A comparison of the related issues is shown in Table 9.

In the control of industrial processes, hybrid or heuristic models have long been used; they enjoy great popularity giving better results than uniform tools [47-52]. The integration of input data [53] or of the results of such differentiated solutions is a separate issue, where an important role will have the semantic modelling, including ontologies [54], but this is the topic for an entirely new publication.

Acknowledgements Financial support of The National Centre for Research and Development LIDER/028/593/L-4/12/NCBR/2013 is gratefully acknowledged.

Open Access This article is distributed under the terms of the Creative Commons Attribution 4.0 International License (http:// creativecommons.org/licenses/by/4.0/), which permits unrestricted use, distribution, and reproduction in any medium, provided you give appropriate credit to the original author(s) and the source, provide a link to the Creative Commons license, and indicate if changes were made. 


\section{References}

1. Witten I, Frank E (2000) Data mining: practical machine learning tools and techniques. Morgan Kaufmann, New York

2. Glowacz A (2016) Fault diagnostics of DC motor using acoustic signals and MSAF-RATIO30-EXPANDED. Arch Electr Eng 65(4):733-744

3. Quinlan JR (1986) Induction on decision trees, machine learning. Kluwer Academic Publishers, Boston

4. Balasubramanian SA, Manickavasagam J, Natarajan T, Balakrishnan J (2015) An experimental analysis of forecasting the high frequency data of matured and emerging economies stock index using data mining techniques. Int J Oper Res 23(4):406-426

5. Wilk-Kolodziejczyk D, Regulski K, Gumienny G (2016) Comparative analysis of the properties of the Nodular Cast Iron with Carbides and the Austempered Ductile Iron with use of the machine learning and the Support Vector Machine. Int J Adv Manuf Technol 87(1):1077-1093

6. Regulski K, Szeliga D, Kusiak J (2014) Data exploration approach versus sensitivity analysis for optimization of metal forming processes. Key Eng Mater 611612:1390-1395

7. Kluska-Nawarecka S, Wilk-Kolodziejczyk D, Regulski K, Dobrowolski G (2011) Rough sets applied to the rough-cast system for steel castings. In: Nguyen NT, Kim C-G, Janiak A (eds) Intelligent information and database systems. Part II. Lecture notes in computer science, vol 6592, no 2011. Springer, pp 52-61

8. Pietrowski S (1998) Alloyed cast iron with compacted graphite. Solidification Met Alloys 37:105-111

9. Guzik E (2006) Selected issues on the structure and properties of ausferritic cast iron. Arch Foundry Eng 21(1/2):33-42

10. Founding - Compacted (compacted) graphite cast irons PN-EN 16079:2012

11. Skvarenina S, Shin YC (2006) Laser-assisted machining of compacted graphite iron. Int J Mach Tools Manuf 46(1):7-17

12. Pietrowski S (2000) Compendium of knowledge about compacted cast iron. Solidification Met Alloys 2(44):279-292

13. Cueva G, Sinatora A, Guesser WL, Tschiptschin AP (2003) Wear resistance of cast irons used in brake disc rotors. Wear 255:12561260

14. Guzik E, Dzik S (2009) Structure and mechanical properties of compacted cast iron in cylinder head casting. Arch Foundry Eng 9(1):175-18

15. Guzik E, Kleingartner T (2009) A study on the structure and mechanical properties of compacted cast iron with pearliticferritic matrix. Arch Foundry Eng 9(3):55-60

16. Sun XJ, Li YX, Chen X (2007) Controlling melt quality of compacted graphite iron. Mater Sci Eng A 466(1):1-8

17. Pietrowski S (1998) A mechanism of the compacted graphite crystallization in cast iron. Solidification Met Alloys 37:97-104

18. Mierzwa P, Soiński M (2011) The effect of thermal treatment on the mechanical properties of compacted cast iron. Arch Foundry Eng Spec Issue 10(1):133-138

19. Andrsova Z, Volesky L (2012) The potential of isothermally hardened iron with compacted graphite. COMAT 2012, Plzeň

20. Pytel A, Gazda A (2014) Evaluation of selected properties in austempered compacted cast iron (AVCI). Trans Foundry Res Inst 54(4):23-31

21. Soinski MS, Jakubus A (2014) Initial assessment of abrasive wear resistance of austempered cast iron with compacted graphite. Arch Metall Mater 59(3):1073-1076

22. Onal O, Ozturk AU (2010) Artificial neural network application on microstructure-compressive strength relationship of cement mortar. Adv Eng Softw 41(2):165-169
23. Cruz D, Talbert DA, Eberle W, Biernacki J (2016) A neural network approach for predicting microstructure development in cement. In: International conference of artificial intelligence ICAI

24. Sundararaghavan V, Zabaras N (2005) Classification and reconstruction of three-dimensional microstructures using support vector machines. Comput Mater Sci 32(2):223-239

25. Ramkishore S, Madhumitha P, Palanichamy P (2015) Comparison of logistic regression and support vector machine for the classification of microstructure and interfacial defects in zircaloy2. In: International conference on soft computing and machine intelligence (ISCMI)

26. Rauch L, Chmura A, Gronostajski Z, Polak S, Pietrzyk M (2016) Cellular automata model for prediction of crack initiation and propagation in hot forging tools. Arch Civ Mech Eng 16(3):437447

27. Yang H, Wu Ch, Li HW, Fan XG (2011) Review on cellular automata simulations of microstructure evolution during metal forming process: Grain coarsening, recrystallization and phase transformation. Sci China Technol Sci 54(8):2107-2118

28. Pietrowski S Influence of reaction chamber shape on cast iron spheroidization process in-mold. Arch Foundry Eng 10(1):115-122

29. Friedman JH (1991) Multivariate adaptive regression splines. Ann Stat 19(1):1-67

30. Abraham A, Steinberg D, Philip NS (2001) Rainfall forecasting using soft computing models and multivariate adaptive regression splines. IEEE SMC Trans Special Issue Fusion Soft Comput Hard Comput Ind Appl 1:1-6

31. Butte NF, Wong WW, Adolph AL, Puyau MR, Vohra FA, Zakeri IF (2010) Validation of cross-sectional time series and multivariate adaptive regression splines models for the prediction of energy expenditure in children and adolescents using doubly labeled water. J Nutr 140(8):1516-1523

32. De Andrs J, Lorca P, de Cos Juez F, Snchez-Lasheras F (2011) Bankruptcy forecasting: a hybrid approach using fuzzy c-means clustering and multivariate adaptive regression splines (MARS). Expert Syst Appl 38(3):1866-1875

33. Plonsky L, Oswald FL (2016) Multiple Regression as a flexible alternative to ANOVA in L2 research. Stud Second Lang Acquis 39(3): $1-14$

34. Behera AK, Verbert J, Lauwers B, Duflou JR (2013) Tool path compensation strategies for single point incremental sheet forming using multivariate adaptive regression splines. Comput-Aided Des 45(3):575-590

35. Mukhopadhyay A, Iqbal A (2009) Prediction of mechanical property of steel strips using multivariate adaptive regression splines. J Appl Stat 36(1):1-9

36. Beccali M, Cellura M, Brano VL, Marvuglia A (2004) Forecasting daily urban electric load profiles using artificial neural networks. Energy Convers Manag 45:2879-2900

37. Hippert H, Pedreira CE, Souza RC (2001) Neural networks for short term load forecasting: a review and evaluation. IEEE Trans Power Syst 16:44-55

38. Jakubski J, Malinowski P, Dobosz StM, Major-Gabryś K (2013) ANN Modelling for the analysis of the Green Moulding Sands properties. Arch Metall Mater 58(3):961-964

39. Sztangret L, Szeliga D, Kusiak J, Pietrzyk M (2012) Application of inverse analysis with metamodelling for identification of metal flow stress. Can Metall Q 51:440-446

40. Rauch L, Sztangret L, Pietrzyk M (2013) Computer system for identification of material models on the basis of plastometric tests. Arch Metall Mater 58(3):737-743

41. Tomar D, Agarwal S (2015) A comparison on multi-class classification methods based on least squares twin support vector machine. Knowl-Based Syst 81:131-147 
42. Laurain V (2015) An instrumental least squares support vector machine for nonlinear system identification. Automatica 54:340 347

43. Santos CM, Escobedo JF, Teramoto ÉT, Silva SH (2016) Assessment of ANN and SVM models for estimating normal direct irradiation $(\mathrm{Hb})$. Energy Convers Manag 126:826-836

44. Breinman L, Friedman JH, Olshen RA, Stone CJ (1993) Classification and regression trees. Chapman and Hall, UK

45. Kass GV (1980) An exploratory technique for investigatin large quantities of categorical data. Appl Stat 29:119-127

46. Regulski K, Jakubski J, Opaliński A, Brzeziński M, Gowacki M (2016) The prediction of moulding sand moisture content based on the knowledge acquired by data mining techniques. Arch Metall Mater 61(3):1363-1368

47. Kluska-Nawarecka S, Gorny Z, Wilk-Kolodziejczyk D (2007) The logic of plausible reasoning in the diagnosis of castings defects. Arch Metall Mater 52(3):375-380

48. Gorny Z, Kluska-Nawarecka S, Wilk-Kolodziejczyk D (2013) Heuristic models of the toughening process to improve the properties of non-ferrous metal alloys. Arch Metall Mater 58(3):849-852
49. Smyksy K, Ziolkowski E, Wrona R, Brzezinski M (2013) Performance evaluation of rotary mixers through monitoring of power energy parameters. Arch Metall Mater 58(3):911-914

50. Maciol P, Regulski K (2016) Development of semantic description for multiscale models of thermo-mechanical treatment of metal alloys. JOM 68(8):2082-2088

51. Maciol A, Wrona R, Stawowy A, Maciol P (2007) An attempt at formulation of ontology for technological knowledge comprised in technical standards. Arch Metall Mater 52(3):381388

52. Rojek G, Kusiak J (2012) Industrial control system based on data processing. Lect Notes Comput Sci 7268:502-510

53. Kluska-Nawarecka S, Wilk-Kolodziejczyk D, Dajda J, Macura M, Regulski K (2014) Computer-assisted integration of knowledge in the context of identification of the causes of defects in castings. Arch Metall Mater 59(2):743-746

54. Kluska-Nawarecka S, Regulski K, Krzyzak M, Lesniak G, Gurda M (2013) System of semantic integration of non-structuralized documents in natural language in the domain of metallurgy. Arch Metall Mater 58(3):927-930 